\title{
Deletions of $16 q$ in Wilms Tumors Localize to Blastemal-Anaplastic Cells and Are Associated with Reduced Expression of the IRXB Renal Tubulogenesis Gene Cluster
}

\author{
Linda Holmquist Mengelbier, ${ }^{*}$ Jenny Karlsson, ${ }^{*}$ \\ David Lindgren, ${ }^{\dagger}$ Ingrid Øra, ${ }^{\neq \S}$ \\ Margareth Isaksson, ${ }^{*}$ Ildiko Frigyesi, ${ }^{\text {* }}$ \\ Attila Frigyesi, " Johannes Bras," \\ Bengt Sandstedt, ${ }^{* *}$ and David Gisselsson*†† \\ From the Departments of Clinical Genetics, ${ }^{*}$ and Pathology, \\ University and Regional Laboratories, Pediatric Oncology, ${ }^{\ddagger}$ and \\ Anesthesiology, "Lund University, Skåne University Hospital, \\ Lund, Sweden; the Center for Molecular Pathology, ${ }^{\dagger}$ the \\ Department of Laboratory Medicine, Lund University, Skåne \\ University Hospital, Malmö, Sweden; the Departments of Human \\ Genetics, ${ }^{\S}$ and Pathology," Academic Medical Center, University \\ of Amsterdam, Amsterdam, The Netherlands; and the Childhood \\ Cancer Research Unit, ${ }^{* *}$ Astrid Lindgren's Children's Hospital, \\ Karolinska Institutet, Stockbolm, Sweden
}

Wilms tumor is the most common pediatric renal neoplasm, but few molecular prognostic markers have been identified for this tumor. Somatic deletion in the long arm of chromosome 16 (16q) is known to predict a less favorable outcome in Wilms tumor, but the underlying molecular mechanisms are not known. We show that $\mathbf{1 6 q}$ deletions are typically confined to immature anaplastic-blastic tumor elements, while deletions are absent in maturing tumor components. The smallest region of deletion overlap mapped to a 1.8-Mb segment containing the IRXB gene cluster including IRX3,IRX5, and IRX6, of which IRX 3 is a recently identified regulator of tubular maturation during nephrogenesis. Tumors with 16q deletion showed a lower overall mRNA expression of IRXB genes, and 16q-deleted tumor cells failed to express IRX3 while it was expressed in differentiating tubular tumor elements with intact 16q. Consistent with a role for $I R X 3$ in tubular differentiation, gene sets linked to Notch signaling, Rho signaling, and ion channel activity were enriched in tumors with high IRX3 expression, while WTs with low expression were enriched for gene sets linked to cell cycle progression.
Low mRNA levels of IRXB genes were associated with diffuse anaplasia, high-stage disease, and death. A disturbed balance between tubular differentiation and selfrenewal of anaplastic-blastic elements may thus be one mechanism linking $16 \mathrm{q}$ deletion to adverse outcome in Wilms tumor. (Am J Pathol 2010, 177:2609-2621; DOI: 10.2353/ajpath.2010.100130)

Wilms tumor accounts for more than 95\% of kidney tumors in children. The majority of patients receiving modern multimodal therapy are cured, but 10 to $15 \%$ still die of disease. ${ }^{1}$ Histologically, most WTs mimic the fetal developing kidney in which immature cells of the metanephric mesenchyme differentiate into stromal and epithelial elements, the latter of which ultimately give rise to the nephronic tubules and glomeruli. ${ }^{2}$ The notion that Wilms tumor originates from pluripotent immature cells is supported by its characteristic triphasic histology, including blastemal, epithelial, and stromal components. The blastema consists of undifferentiated mesenchymal cells, resembling the metanephric mesenchyme, while the epithelial component might show different degrees of differentiation, including primitive tubular and glomeruloid formations. Gene expression studies have provided additional evidence for the hypothesis that Wilms tumor results from a differentiation block in embryonic kidney formation; genes overexpressed in Wilms tumor are also

Supported by the Swedish Childhood Cancer Foundation, the Swedish Cancer Society, the Swedish National Research Council, the Lund University Hospital Donation Funds, the Gunnar Nilsson Cancer Foundation, the Crafoord Foundation, the Erik-Philip Sörensen Foundation, the Lundgren Foundation, the Schyberg Foundation, and the Medical Faculty at Lund University

Accepted for publication July 6, 2010.

Supplemental material for this article can be found on http://ajp. amjpathol.org.

Address reprint requests to David Gisselsson, M.D., Ph.D., Department of Clinical Genetics, Lund University, University Hospital, SE 22185 Lund, Sweden. E-mail: david.gisselsson_nord@med.lu.se. 
expressed at the time of the first contact between the ureteric bud and the metanephric mesenchyme, while genes underrepresented in WTs are typically expressed later in kidney development. ${ }^{3,4}$ The origin of WTs from potential renal precursors is also supported by the association of Wilms tumor with persistent patches of embryonic tissue in adjacent normal kidney tissue, known as nephrogenic rests. ${ }^{5}$

Considering the similarities between Wilms tumor and the developing kidney, it is not surprising that several of the genes affected by somatic mutations in WTs are involved in embryonic kidney development and have been implicated in syndromes of genito-urinary malformation. For example, 10 to $20 \%$ of sporadic WTs have inactivating mutations in WT1. ${ }^{2}$ WT1 has a key role in the induction of ureteric branching and survival of the metanephric mesenchyme. ${ }^{6}$ Tumors exhibiting WT1 abnormalities frequently also contain mutations of CTNNB1 leading to activation of the WNT signaling pathway, which is critical for the induction of epithelial differentiation in the metanephric mesenchyme. ${ }^{7,8}$ Another gene involved in WNT signaling, the FAM123B gene (WTX), has also been reported to be mutated in WTs. ${ }^{9,10}$ While WT1 mutations have been found to occur already in the nephrogenic rests assumed to be Wilms tumor precursor lesions, CTNNB1 and FAM123B alterations probably occur later in tumorigenesis. ${ }^{11-13}$ Even though genetic alterations of at least one of the genes WT1, CTNNB1, and FAM123B are present in approximately one third of sporadic WTs, ${ }^{14}$ none of these genes have been found to have an impact on disease course, and they have failed to qualify as prognostic markers. ${ }^{2,13}$

The similarities between the blastemal elements in Wilms tumor and the metanephric mesenchyme indicate that blastemal cells not only act as precursors for the differentiated stromal end epithelial elements but may also be responsible for maintenance of the tumor cell population by self-renewal and potential progression toward metastatic disease and death. Indeed, for Wilms tumor patients subjected to preoperative chemotherapy, it has been shown that tumors with a predominance of blastemal cells after treatment have a less favorable outcome than those dominated by stromal or epithelial elements with a small amount of blastema or tumors containing an even mix of all three elements (mixed type). ${ }^{15-17}$ A poor outcome has also been shown for tumors with widespread, well-defined strong nuclear atypia and the presence of large abnormal mitoses, socalled diffuse anaplasia. ${ }^{15,16}$ Little is known about the molecular mechanisms responsible for the expansion or maintenance of blastemal cells resulting in the blastemal predominant phenotype and even less about the biological changes leading to anaplasia. Few molecular markers predicting the development of metastatic disease and death of children with Wilms tumor have so far been established. One exception is loss of heterozygosity/ hemizygous deletion in the long arm of chromosome 16 (16q), which has been shown in several studies to predict metastatic disease and death in patients having undergone either up-front surgery or surgery preceded by chemotherapy. ${ }^{18-22}$ However, the molecular pathways linking $16 q$ deletion to an aggressive tumor phenotype have been little explored.

In the present study, we have attempted to clarify the role of $16 q$ deletion in the development of an aggressive tumor phenotype in Wilms tumor. We show that $16 \mathrm{q}$ deletions are confined to the immature blastemal and anaplastic-blastemal tumor elements. We further demonstrate that the smallest region of overlap for $16 q$ deletions in our material contains the IRXB gene cluster (IRX3, IRX5, and IRX6), of which IRX3 has recently been shown to act as a master regulator of intermediate tubule fate and to be necessary and sufficient to specify nephron segment identity in the developing kidney. ${ }^{23}$ Blastemal and anaplastic elements exhibiting loss of $16 \mathrm{q}$ failed to express the IRX3 protein, in contrast to epithelial and blastemal elements with intact $16 q$ copies. Tumors with $16 q$ deletion showed a lower overall mRNA expression of IRX3 as well as of the other IRXB genes. High IRX3 mRNA expression was associated with low-risk clinico-pathological features and a gene signature consistent with a role in maintaining a capacity for tubular differentiation. In contrast, low IRX3 expression was associated with highrisk features and a gene expression signature dominated by genes involved in mitotic cell cycle progression. Based on this, we suggest that a disturbed balance between epithelial maturation and self-renewal of immature elements may be one important route through which $16 \mathrm{q}$ deletion promotes development of aggressive disease in Wilms tumor patients.

\section{Materials and Methods}

\section{Tumor Material and Cell Culture}

Wilms tumor tissue was obtained from 24 patients treated at Lund University Hospital, Lund, Sweden and from 14 patients treated at the Academic Medical Center (AMC), Amsterdam, the Netherlands (Table 1). The ethics review boards of the participating institutes had approved the study, and genetic analyses were performed after parental informed consent. Histological classification was made initially by the local pathologists (D.G., J.B.) and reviewed by a reference pathologist of the SIOP Pathology Review Panel (B.S.). Risk stratification was performed according to SIOP guidelines, ${ }^{16}$ with revision of risk group when pertinent for cases diagnosed before 2002. Patients were treated according to standard SIOP protocols, with nephrectomy preceded by chemotherapy. Cytogenetic analyses of peripheral blood lymphocytes and tumor tissue were performed according to standard methods. ${ }^{24}$ WiT49 cells, derived from a diffusely anaplastic Wilms tumor, were provided by Dr. Yeger at the Laboratory of Medicine and Pathobiology, University of Toronto, Canada, ${ }^{25}$ and HEK293 cells were obtained from the Cell Bank Interlab Cell Line Collection (Genova, Italy). Cells were cultured in DMEM/F-12 (1:1), $10 \%$ fetal bovine serum, $100 \mathrm{IJ} / \mathrm{ml}$ penicillin $\mathrm{V}$, and 100 $\mu \mathrm{g} / \mathrm{ml}$ streptomycin. As references in real-time quantitative PCR experiments, total fetal kidney RNA pooled from 34 Caucasian spontaneously aborted fetuses, ages 
Table 1. Clinical and Histopathological Data

\begin{tabular}{|c|c|c|c|c|c|c|c|c|}
\hline Case* & Age (months) & $\operatorname{Sex}^{+}$ & Size $(\mathrm{cm})^{\ddagger}$ & Risk group ${ }^{\S}$ & Stage & Histology $y^{\pi}$ & Outcomell & Follow-up time (weeks) \\
\hline 1 & 12 & $\mathrm{~F}$ & & IR & II & $\mathrm{R}$ & NED & 168 \\
\hline 2 & 7 & M & 11.0 & $\mathrm{IR}$ & I & M & NED & 89 \\
\hline 3 & 36 & $\mathrm{M}$ & 20.0 & IR & III & $\mathrm{M}$ & NED & 131 \\
\hline 4 & 31 & $\mathrm{~F}$ & 7.0 & $\mathrm{HR}$ & V & DA & DOD & 55 \\
\hline 5 & 12 & $\mathrm{M}$ & 7.0 & IR & I & $\mathrm{M}$ & NED & 93 \\
\hline 6 & 76 & $\mathrm{M}$ & 10.0 & IR & i & S & NED & 82 \\
\hline 7 & 60 & $\mathrm{~F}$ & 18.0 & $\mathrm{HR}$ & IV & DA & DOD & 33 \\
\hline 8 & 109 & $\mathrm{~F}$ & $\mathrm{n} / \mathrm{d}$ & $\mathrm{IR}$ & III & $\mathrm{E}$ & NED & 56 \\
\hline 9 & 49 & $\mathrm{~F}$ & 12.0 & IR & IV & $\mathrm{R}$ & NED & 56 \\
\hline 10 & 9 & $\mathrm{~F}$ & 11.0 & $\mathrm{IR}$ & I & $\mathrm{M}$ & NED & 132 \\
\hline 11 & 29 & M & 13.0 & $\mathrm{IR}$ & I & M & NED & 41 \\
\hline 12 & 60 & $\mathrm{~F}$ & 9.4 & $\mathrm{HR}$ & IV & $\mathrm{B}$ & NED & 51 \\
\hline 13 & 34 & $M$ & 8.0 & $\mathrm{IR}$ & 1 & $\mathrm{R}$ & NED & 83 \\
\hline 14 & 29 & $\mathrm{~F}$ & 10.5 & $\mathrm{HR}$ & I & DA & NED & 141 \\
\hline 15 & 54 & $\mathrm{M}$ & 15.0 & $\mathrm{HR}$ & V & B & DOD & 56 \\
\hline 16 & 34 & $\mathrm{~F}$ & 13.0 & IR & i & $\mathrm{M}$ & NED & 890 \\
\hline 17 & 96 & $M$ & 12.0 & IR & I & $\mathrm{R}$ & NED & 750 \\
\hline 18 & 25 & $\mathrm{~F}$ & 10.0 & IR & i & $S$ & NED & 797 \\
\hline 19 & 11 & $\mathrm{~F}$ & 12.0 & IR & V & $S$ & NED & 450 \\
\hline 20 & 49 & $\mathrm{~F}$ & 15.0 & IR & i & $S$ & NED & 393 \\
\hline 21 & 66 & $\mathrm{~F}$ & 17.0 & $\mathrm{IR}$ & 1 & $\mathrm{M}$ & DOD & 137 \\
\hline 22 & 69 & $\mathrm{M}$ & 13.0 & $\mathrm{HR}$ & IV & B & DOD & 72 \\
\hline 23 & 46 & $\mathrm{~F}$ & 6,5 & IR & II & $\mathrm{M}$ & NED & 251 \\
\hline 24 & 43 & $M$ & 10.0 & IR & II & $\mathrm{R}$ & NED & 273 \\
\hline 25 & 21 & $M$ & 12.0 & IR & i & $M$ & NED & 229 \\
\hline 26 & 24 & $\mathrm{~F}$ & 11.0 & IR & I & M-FA & NED & 245 \\
\hline 27 & 42 & $M$ & 10.0 & $\mathrm{IR}$ & II & $\mathrm{M}$ & NED & 218 \\
\hline 28 & 12 & $\mathrm{~F}$ & 13,8 & $\mathrm{HR}$ & 1 & B & NED & 176 \\
\hline 29 & 13 & $M$ & 11.0 & $\mathrm{IR}$ & II & $M$ & NED & 138 \\
\hline 30 & 76 & $\mathrm{~F}$ & 10.0 & IR & III & $\mathrm{R}$ & NED & 76 \\
\hline 31 & 86 & $M$ & 3.0 & LR & III & $\mathrm{CN}$ & NED & 67 \\
\hline 32 & 119 & $\mathrm{~F}$ & 13.0 & $\mathrm{IR}$ & III & $\mathrm{R}$ & DOD & 801 \\
\hline 33 & 5 & $\mathrm{M}$ & 9.0 & IR & 1 & $E$ & NED & 889 \\
\hline 34 & 15 & $M$ & 3.5 & $\mathrm{IR}$ & I & $\mathrm{B}$ & NED & 1051 \\
\hline 35 & 118 & $\mathrm{~F}$ & 14.0 & $\mathrm{HR}$ & । & DA & NED & 757 \\
\hline 36 & 19 & $\mathrm{~F}$ & 10.0 & $\mathrm{HR}$ & i & B & NED & 911 \\
\hline 37 & 134 & $\mathrm{~F}$ & 13.0 & $\mathrm{HR}$ & V & B & NED & 104 \\
\hline 38 & 41 & $\mathrm{~F}$ & 20.0 & LR & V & B & DOD & 44 \\
\hline
\end{tabular}

${ }^{*}$ Cases with $16 q$ deletions are in bold type.

${ }^{\dagger} \mathrm{M}$, male; F, female.

¥ Maximum tumor diameter

$\S \mathrm{R}$, intermediate risk; HR, high risk; LR, low risk

${ }^{T} R$, regressive type; $M$, mixed type; DA, diffuse anaplasia; $S$, stromal type; $B$, blastemal type; $R$, regressive type; FA, focal anaplasia; CN, completetly necrotic. Histological types and risk groups are according to the revised International Society of Paediatric Oncology (SIOP) working classification of renal tumors of childhood.

"NED, no evidence of disease at latest follow-up; DOD, dead of disease.

12-31 weeks (cat. No. 636584) and total adult kidney RNA from a normal human kidney from a 40-year-old Caucasian female (cat. No. 636529) were used (Clontech, Mountain View, CA).

\section{Fluorescence in Situ Hybridization (FISH) and Immunofluorescence}

Tissue sections of $4 \mu \mathrm{m}$ were prepared on positively charged microscopy slides according to standard procedures and deparaffinized in xylene for $3 \times 5$ minutes, followed by rehydration in a graded ethanol series, and washing in phosphate-buffered saline. Target DNA accessibility was increased by treatment for 15-25 minutes in antigen retrieval buffer (DAKO, Glostrup, Denmark) at $125^{\circ} \mathrm{C}$. This was followed by $20 \mathrm{mg} / \mathrm{ml}$ pepsin treatment for 5 minutes at $37^{\circ} \mathrm{C}$ in $0.01 \mathrm{M} \mathrm{HCl}$, wash in saline, and dehydration before codenaturation of probe and target
DNA at $84^{\circ} \mathrm{C}$ for 10 minutes. Areas containing at least 30 nuclei were evaluated for copy number by comparing the total number of centromere probe signals for chromosome 16 with the number of signals for a $16 q$ probe. $16 q$ was detected by LSI MAF 16q23 (SpectrumOrange), and the chromosome 16 centromere detected by CEP 16 (D16Z3; SpectrumAqua) was used as a copy number control (both from Abbott Molecular, Abbott Park, IL). The 99,459,993-105,471,114 segment in chromosome 6 was detected by the overlapping bacterial artificial chromosome clones RP11-460L11 and RP11-124M11 in case 26. Reference values for normal $16 q$ and $6 q$ copy-numbers compared to the centromeric probe (expected ratio $2: 2)$ were calculated as $1.0 \pm 2 \times$ (coefficient of variance) in cells located in nonneoplastic kidney parenchyma, typically resulting in reference intervals of $0.8-1.2$, while reference numbers for loss of one $16 q$ copy (expected ratio 1:2) were calculated as $0.5 \pm 2 \times$ (coefficient of 
variance) typically resulting in reference intervals of $0.4-$ 0.6. Detection of IRX3 protein expression by immunofluorescence with the mouse monoclonal antibody ab57735 at a concentration of 1:50 (Abcam, Cambridge, UK) was performed as previously described, ${ }^{26}$ on Wilms tumor tissue sections, pretreated for 15-25 minutes in antigen retrieval buffer (DAKO).

\section{SNP-Based Array Comparative Genomic Hybridization (aCGH)}

For high-resolution detection of genomic imbalances, $300 \mathrm{ng}$ of DNA was extracted using standard methods (DNeasy Blood \& Tissue Kit, Qiagen, Valencia, CA) and hybridized to Illumina HumanCNV370-Duo/Quad Genotyping BeadChips (Illumina Inc., San Diego, CA) according to the manufacturer's specifications. Allele-specific fluorescent signals were first normalized using a proprietary algorithm in the Illumina BeadStudio software (Illumina Inc). Normalized allelic intensity values were then exported and subjected to an additional normalization step using the tQN-software. ${ }^{27}$ By applying a thresholdmodified quantile normalization algorithm, this method corrects for the dye-dependent asymmetry between the two different fluorescent channels that has been observed in Illumina Infinium data. The tQN software was also used to estimate B-allele frequencies (BAF) for each SNP based on a set of reference genotype clusters. For identification of imbalances, the BAF segmentation software was used, in which BAF-values are transformed into mirrored BAF (mBAF) values followed by removal of noninformative homozygous SNPs by a fixed mBAF threshold. ${ }^{28}$ BAF segmentation also applies a segmentation algorithm on the mBAF data to define regions of allelic imbalance. For each resulting segment, a copy number estimate was also given as the median log2 ratio of all SNPs present within the defined segment. Segments with mBAF values $>0.55$ were classified as being in allelic imbalance. Segments with log2 ratio $>0.073$ were classified as genomic gains, those with $\log 2$ ratios $<-0.080$ as genomic losses, and those with log2 ratios between these boundaries as copy number neutral genomic imbalances. ${ }^{28}$ These threshold values were adopted from a previous evaluation of our platform for genomic analysis and were selected to maximize signal to noise ratio while retaining a detection level for allelic imbalances present in approximately $>20 \%$ of the cells. ${ }^{28}$ Copy number imbalances that were not associated with allelic imbalances (eg, 4 copies at a 2:2 ratio) were identified by visual inspection of log2 ratio plots. Segments were fused if the interspersed genomic distance was $<1 \mathrm{Mb}$ and the difference in mBAF values between the segments was $<0.1$. Constitutional copy number variants were excluded from the final data by comparison to the Database of Genomic Variants (http://projects.tcag.ca/variation/, last accessed June 1, 2009). Segmented SNP-array data, without constitutional variants and other patient-specific genotype information, are included in Supplemental Table 1 (at http://ajp.amjpathol.org).

\section{Transfection}

To determine subcellular localization of the IRX3 protein, HEK293 and WiT49 cells were transfected with a full open reading frame expression clone (IOH27948-pdEYFPN1gen, Imagines GmbH, Berlin, Germany). Transfection was performed using FuGENE Transfection Reagent according to the manufacturer's suggestions (Roche Diagnostics $\mathrm{GmbH}$, Mannheim, Germany). In brief, 500,000 cells were seeded in DMEM with $10 \%$ fetal bovine serum and the next day transfected with a complex formed between the open reading frame expression clone and FuGENE HD transfection reagent. Cells were incubated for either 24 hours or 48 hours followed by mounting and protein localization using fluorescence microscopy.

\section{Quantitative Real-Time PCR}

The relative levels of mRNA expression in tumor material were determined by real-time quantitative PCR based on $5^{\prime}$ nuclease chemistry using TaqMan MGB minor groove binder probes. TaqMan Gene Expression Assays from Applied Biosystems (Life Technologies, Carlsbad, CA) were used (Supplemental Table 2 at $h$ ttp://ajp.amjpathol.org). Total RNA was extracted from frozen tumor material using the RNeasy Lipid Tissue Mini Kit (Qiagen, Valencia, CA) followed by On-column DNase Digestion (Qiagen). Total RNA was used to synthesize cDNA with random hexamers and Moloney murine leukemia virus reverse transcriptase (Invitrogen, Carlsbad, CA). For normalization of expression data, four house keeping genes (SDHA, ALAS1, ACTB, and GUSB) were used as reference genes. These genes had been selected from a panel of 11 tested genes (Supplemental Table 2 at $h$ ttp://ajp.amjpathol.org, genes 1-11) using the geNorm software to determine the most stable reference genes for use in analyses of Wilms tumor. ${ }^{29-31}$ The comparative $\mathrm{Ct}$ method was used for relative quantification of expression levels. ${ }^{32}$ IRX3 mRNA expression levels (no. 12 in Supplemental Table 2 at $h$ ttp://ajp.amjpathol.org) were validated in our material using one additional probe set (no. 13 in Supplemental Table 2 at $h$ ttp://ajp.amjpathol.org). This showed a very high correlation to the results of the first probe set (Pearson $r=0.94$ ).

\section{External Dataset Validation}

The external dataset (GEO ID GSE11024) consisted of 27 WTs, ${ }^{33}$ profiled on the Affymetrix HG-U133 Plus 2.0 GeneChip and normalized by the RMA algorithm. Comparisons between groups were made on normalized intensity values by the Mann-Whitney U-test. Tumors with similar expression profiles were identified using principal component analysis in the Qlucore Omics Explorer software (Qlucore AB, Lund, Sweden). For gene set enrichment analysis (GSEA), curated gene sets from the Kyoto Encyclopedia of Genes and Genomes (KEGG) and the Gene Ontology Consortium were used. All analyses were run with 1000 permutations. Unless otherwise specified, a false discovery rate q value of 0.25 was used as a cut-off to select genes for further analyses, in accordance with recommen- 
Table 2. Primers Used for PCR Amplification and Sequencing of IRX3

\begin{tabular}{|c|c|}
\hline Primer name & Primer sequence \\
\hline A_f149 & 5'-GCCCCGTAGAAATGTCAATC-3' \\
\hline A_r852 & $5^{\prime}-$ TGTACGCACATGGAGAAGGA-3' \\
\hline B_f673 & $5^{\prime}-$ TCCCGCAGCTGGTAAGAG-3' \\
\hline B_r1270 & 5'-CAGCTCTAGCTCGCGTTTG-3' \\
\hline $\mathrm{C}_{-} \mathrm{f} 941$ & 5'-CCGTATGGCCAGTACCAGTT-3' \\
\hline C_r2240 & 5'-CAACCTCGGGGTTTCTTACC-3' \\
\hline$r 1466^{\star}$ & 5'-CCGAGTCGCTATTTTTGGAG-3' \\
\hline f1859* & $5^{\prime}$-СTCTCCCTGCTGGGCTCT-3' \\
\hline D_f2069 & 5'-СССТСТCСАСТССTGCTTTC-3' \\
\hline D_r2668 & 5'-TAGGGCGGGGAGATCCTACT-3' \\
\hline E_f2611 & 5'-TACATTGCGACACCTTCCTG-3' \\
\hline E_r3010 & 5'-ACCGGACAAACAAACCTCAC-3' \\
\hline F_f2639 & 5'-CCCCAATCCAAGTAGGATCTC-3' \\
\hline F_r3112 & 5'-CTCGTACAATTTGGTTCACACA-3' \\
\hline
\end{tabular}

*Sequencing only.

dations for GSEA users. Details of the GSEA algorithm are provided at $h$ ttp://www.broadinstitute.org/gsea/.

\section{Genomic Sequencing}

Overlapping fragments covering the coding sequence of IRX3 were amplified by PCR, with genomic DNA extracted from seven WTs as template. DNA extracted from blood from a healthy female was used as a control. Fragments were sequenced at MCLAB (South San Francisco, CA). Sequences deviating from the reference sequence were re-sequenced by use of BigDye ${ }^{\circledR}$ Terminator v1.1 Cycle Sequencing Kits on an ABI PRISM 3100-Avant Genetic Analyzer (Applied Biosystems/Life Technologies). Forward and reverse chromatograms were analyzed using Mutation Surveyor v3.23 (Softgenetics, PA). Primers for amplification and sequencing are listed in Table 2.

\section{Results}

\section{6q Deletions Are Confined to Immature Tumor Tissue Elements}

To identify WTs with chromosome 16 rearrangements, we first performed SNP-based aCGH on a series of 38 WTs using Illumina Infinium Whole Genome Genotyping arrays (Table 1; Supplemental Tables 1 and 3 at http://ajp. amjpathol.org). Array data were then analyzed by the BAF-segmentation algorithm allowing high-resolution detection of genomic imbalances while filtering out a substantial component of constitutional copy number variation by using strict B-allele frequency cut-off levels. In total, genomic abnormalities were found in 29/38 tumors using this approach. Eight tumors with segmental 16q loss of heterozygosity due to deletion were detected (patients 4, 7, 13, 14, 20, 21, 26, and 27 in Table 1). In addition, one tumor (patient 28) exhibited copy-number neutral imbalance of the entire chromosome 16 . Of the eight tumors with 16 q deletion, five $(7,4,14,20$, and 27$)$ were selected for localization of 16q-deleted cell populations in formalin-fixed paraffin-embedded tissue sec- tions by FISH, using a single copy-probe for $16 \mathrm{q}$ in combination with a probe for the centromere of chromosome 16. SNP-based aCGH does not allow detection of centromeric sequences, but previous cytogenetic analyses had shown that the chromosome 16 centromere was not affected by the deletion in any of these cases (data not shown), making it possible to use the centromere as a copy number control region. Because few tumor cell nuclei will remain intact after sectioning of formalin-fixed paraffin-embedded material, the distribution of 16q-deleted cells was mapped by calculating the signal number ratio between the centromeric probe and the 16q probe in foci of 30-100 cells by FISH. After calibration of cut-off thresholds on areas of adjacent normal kidney, this approach readily allowed the demarcation of tumor areas containing 16q deletions (Figure 1, A-C). In all five cases, the cell populations with $16 q$ deletions were localized to either pure blastemal elements or blastemal elements with anaplastic features. However, not all blastemal cell populations analyzed contained the $16 \mathrm{q}$ deletion, and in four of the cases $(4,7,20$, and 27) blastemal cells without deletion were found in nonanaplastic blastemal areas bordering on or closely mixed with stromal and epithelial elements (Figure 1, A and D-F). No cell populations with $16 \mathrm{q}$ deletions were detected in stromal or epithelial tumor elements, including epithelial elements with anaplastic features, or in adjacent nonneoplastic tissue (normal kidney epithelium and urothelium). Deletions were not detected in any of the multiple perilobar nephrogenic rests present in one of the analyzed sections (case 14; Figure $1 G)$. Thus, at least in the sections analyzed from these five cases, cells with $16 q$ deletions were confined to blastemal or blastemal-anaplastic elements and in no case were they present in all of the neoplastic cells (Figure $1 \mathrm{H}$ ). These results are largely consistent with recently published aCGH data on microdissected material, ${ }^{34}$ showing that $16 q$ deletions are typically not present in perilobar nephrogenic rests adjacent to tumors with $16 q$ deletions, suggesting that $16 q$ deletions are late events in Wilms tumor development. Based on these collective data, we hypothesized that $16 \mathrm{q}$ deletions promote a block of differentiation in blastemal cells, preventing differentiation toward more mature tissue elements in favor of self-renewal of blastemal cells and histological progression toward anaplasia.

\section{Identification of a Smallest Region of Overlap for 16q Deletions}

To search for genes that could be involved in a potential differentiation block resulting from $16 \mathrm{q}$ deletion, we used our SNP-based aCGH data to find a smallest region of overlap (SRO) among the eight cases exhibiting deletions (Figure 2). Even though most cases showed a loss of an extensive part of the chromosome arm, an SRO could be delimited by the SNP markers rs836986 and rs6499813, corresponding to the 1.8-Mb interval 54,239,451-55,991,066 in 16q12-21 (Human GRCh37 Assembly). This interval was contingent on a single case (26) with an unbalanced 5;6;16 translocation, 
A

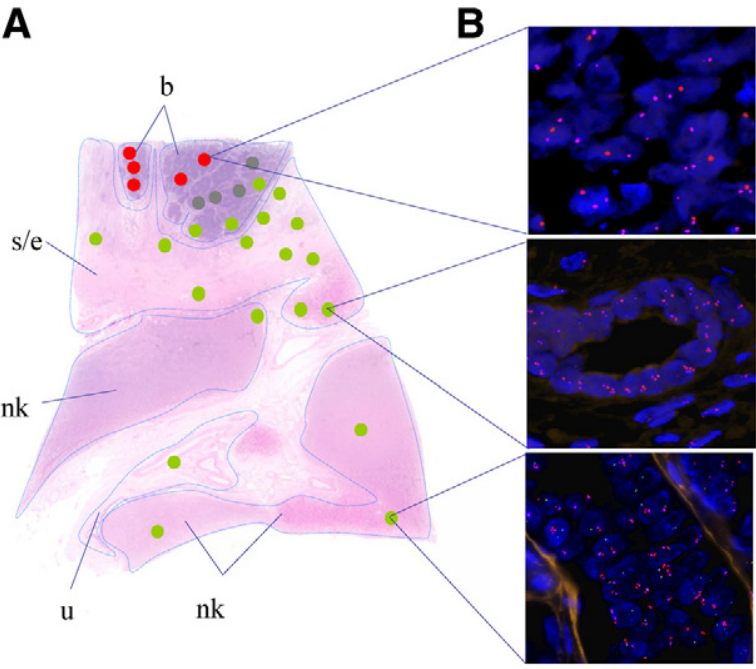

D

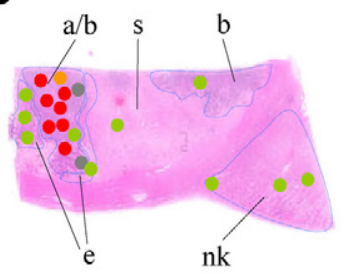

E

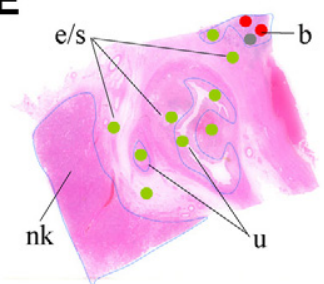

C

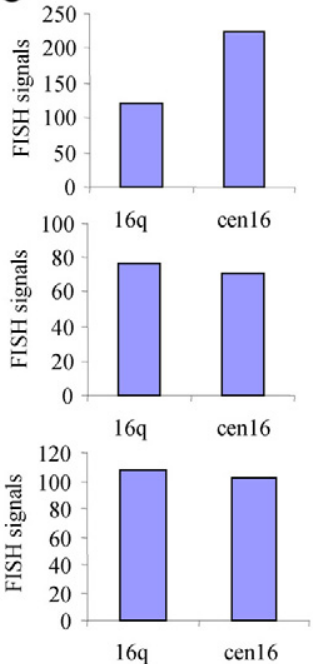

$\mathbf{F}$

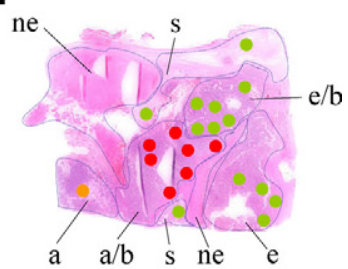

G

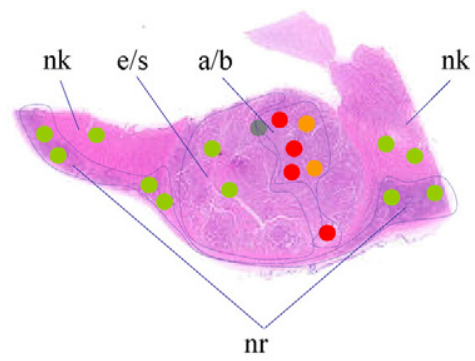

H

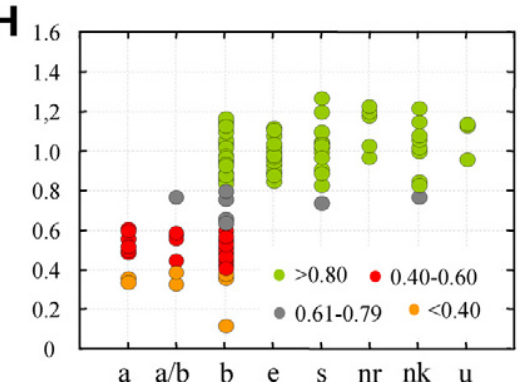

Figure 1. Mapping the spatial distribution of 16q-deleted cells in tumor tissue. The relative copy number of the chromosome 16 centromere and the MAF locus in 16q was determined by scoring centromeric and $M A F$ signals in areas containing 30-100 nuclei. A: Section from a stromal-type Wilms tumor (case 20, Table 1) with foci scored as 16q-deleted (red circles) confined to the center of a blastemal element (b), while the more peripheral portions of the same element contained foci either scored as a mix of 16q-deleted and 16q-intact cells (gray circles) or as 16q-intact cells (green circles); epithelial (e) and stromal (s) tumor elements as well as adjacent normal kidney epithelium (nk) and urothelium (u) contained only populations with normal $16 q$ copy numbers. B: Representative FISH images with signals for the chromosome 16 centromere (violet) and 16q (red) from blastemal (top) and epithelial tumor elements (middle), as well as from normal kidney tubules (bottom). Nuclear staining was obtained with DAPI (blue). C: Examples of signal scores for the $M A F$ locus (16q) and centromere 16 (cen16) from the same tumor as in $\mathbf{A}$ and $\mathbf{B}$, for blastemal (top) and epithelial (middle) tumor elements, as well as for normal kidney tubules (bottom). D: A diffusely anaplastic Wilms tumor (case 7) with 16q deletion confined to anaplastic-blastic $(\mathrm{a} / \mathrm{b})$ elements, but also showing a separate area of blastema without 16q deletion; the orange circle denotes an area with signal ratios below the range expected for hemizygous deletions. E: A mixedtype Wilms tumor (case 27) with 16q deletions confined to a blastemal area. F: Diffusely anaplastic Wilms tumor (case 4) with necrosis (ne), exhibiting $16 \mathrm{q}$ deletions confined mainly to an anaplastic-blastemal element while deletions were not found in an adjacent mixed epithelialblastemal (e/b) element. G: Diffusely anaplastic Wilms tumor (case 14) with 16q deletions confined to a central anaplastic-blastic element and with multiple nephrogenic rests (nr) without 16q deletion. H: Summary of all scored areas in the tumors shown in $\mathbf{A}-\mathbf{G}$, colored according to the ratio of $16 \mathrm{q}$ to centromere (cen) 16 signals. All fluorescence microscopy images were acquired using an $\times 100$ objective and subsequently rescaled digitally. resulting in loss of $6 q$ and $16 q$ sequences, according to previously reported molecular cytogenetic analysis of tumor material. ${ }^{35}$ To ensure that this did not reflect a constitutional chromosome aberration, analysis of peripheral blood lymphocytes from this patient was performed, showing a normal female karyotype. Because of the small size of the deletion in case 26 , it was difficult to obtain $\mathrm{FISH}$ probes of sufficient quality for mapping its $16 \mathrm{q}$ deletion in tumor tissue sections. To localize cells with the unbalanced 5;6;16 translocation we therefore used two overlapping bacterial artificial chromosome clones (RP11-460L11 and RP11-124M11) localizing to the larger deleted interval in $6 q^{35}$ together with a centromeric reference probe to detect populations with the 5;6;16 translocation. This analysis showed that cell populations carrying the unbalanced translocation were confined to a region of blastemal elements with focal anaplasia in this case, whereas epithelial and stromal cell populations showed a normal 6q copy-number (Supplemental Figure 1, A-C at http://ajp.amjpathol.org). Hence, case 26 ap- peared to have similar distribution of cells with $16 q$ deletion as the other cases analyzed on the tissue level.

\section{Identification of IRXB as a Candidate Gene Cluster}

The identified SRO in 16q contained nine mRNA coding sequences (Figure 2). To identify possible candidate genes in the SRO with a role in differentiation block of blastic-anaplastic cells and the development of aggressive disease, a bioinformatic evaluation was first performed using a recently published Wilms tumor mRNA expression microarray dataset, comprising 27 WTs. ${ }^{33}$ We based our analysis on the assumption that a suitable candidate gene should fulfill two criteria: (1) its expression should correlate to clinic-pathological features, and (2) its expression should correlate to genes involved in differentiation/morphogenesis. The external dataset contained mRNA expression profiles of eight of the nine 


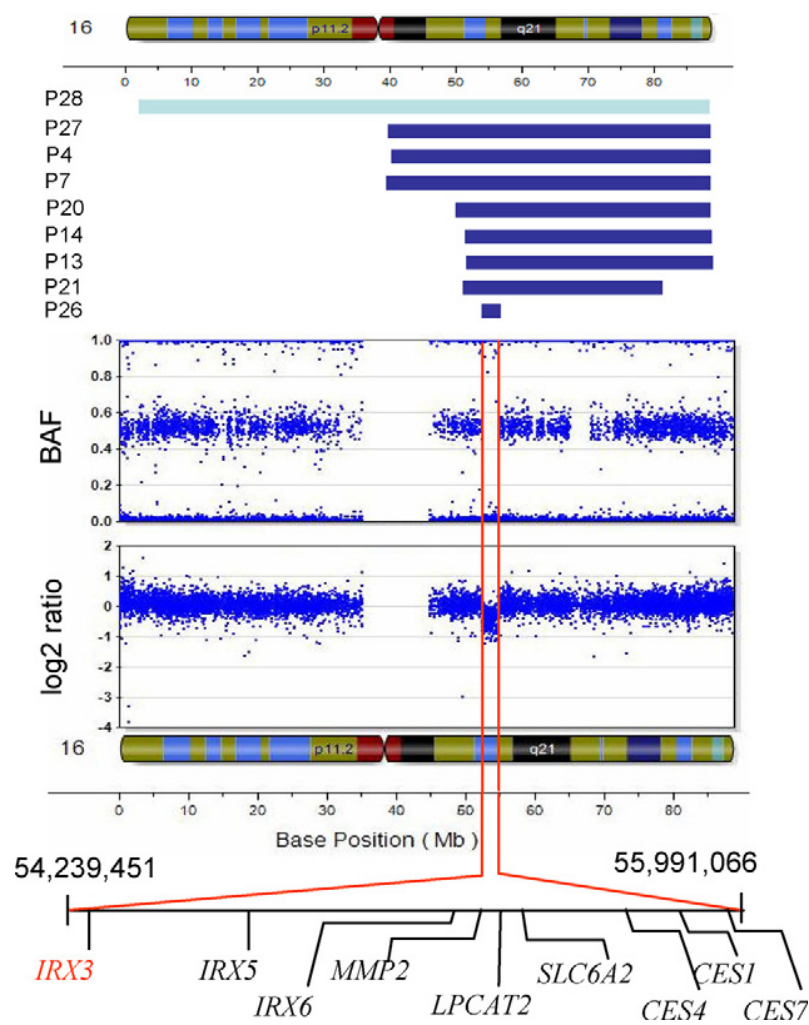

Figure 2. 16q deletions characterized by SNP array. Segments exhibiting hemizygous loss (top section of figure; dark blue bars) and copy-number neutral imbalance (light blue bar) in chromosome 16; patients are denoted by $\mathrm{P}$ followed by their numbers in Table 1 . Below, the smallest region of overlap in $16 \mathrm{q}$ is shown by SNP-based aCGH plots of B-allele frequency (BAF) and $\log _{2}$ ratio for case 26

genes in the SRO (ie, IRX3, IRX5, LPCAT2, SLC6A2, MMP2, CES1, CES4, and CES7). It also contained information on tumor stage. Within this dataset, there was a strong positive correlation between the expression levels of $I R X 3$ and $I R X 5(r=0.74 ; P<0.01)$, while significant correlations could not be found between the expression of other genes in the SRO. The relative expression levels of IRX3 and IRX5 were lower in cases with tumor confined to the kidney compared to those with extra-renal disease (Figure $3 \mathrm{~A}$ and Supplemental Figure 2 at http://ajp. amjpathol.org; $P<0.05$; stages I and II versus stage III; only one case with stage IV was included in the dataset). ${ }^{33}$ None of the other six genes showed any correlation to stage.

To validate these data and to obtain information on the expression of IRX6 (not available from the Affymetrix U133 Plus 2.0 platform used to produce the external dataset), we then performed quantification of mRNA expression levels of IRX3, IRX5, IRX6, LPCAT2, CES1, and $M M P 2$, in the 27 WTs in our series of tumors from which material was available for analysis. SLC6A2, CES4, and CES1 were not evaluated because none of these genes showed any trend whatsoever toward differential expression between cases with intra- and extrarenal disease in the external dataset. Similar to the external dataset, there was a strong positive correlation $(r=0.82 ; P<0.05)$ between IRX3 and IRX5 expression in our series of tumors. There was also a positive correlation between IRX3
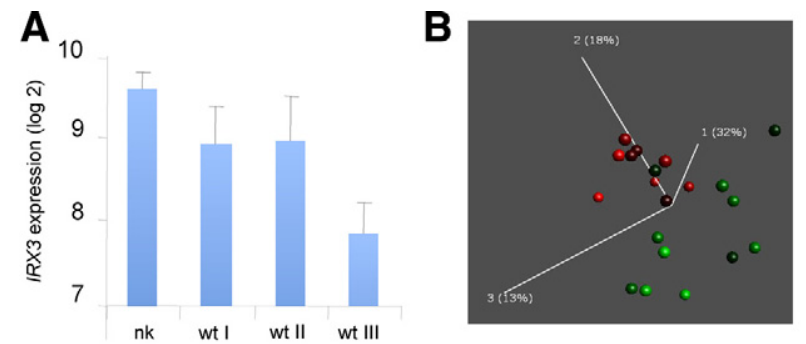

C

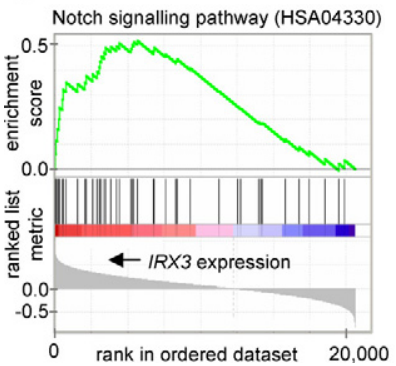

D

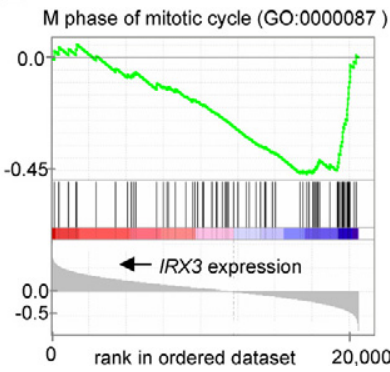

Figure 3. Features of $I R X 3 \mathrm{mRNA}$ expression in an independent dataset. All data were obtained from tumors in the public dataset GSE11024. ${ }^{33} \mathbf{A}: \operatorname{IRX} 3$ expression is lower in tumors from patients with stage III than from stages I and II disease; data were only available for one stage-IV patient. Error bars denote $95 \%$ confidence intervals. wt, Wilms tumors; nk, normal kidney. B: Principal component analysis based on gene expression in individual tumors revealed a clustering of WTs with high (red) and low (green) IRX3 expression; cases were dichotomized according to rank-ordered relative IRX 3 expression and the analysis filtered to contain only those reporters showing $50 \%$ or more of the maximum variance. $\mathbf{C}$ and $\mathbf{D}$ : Representative gene set enrichment plots based on gene lists ranked according to Pearson correlation to IRX3 expression. In each graph, the top portion of the plot shows the running enrichment score for the gene set as the analysis walks down the ranked list. The score at the peak of the plot is the enrichment score for the gene set. The middle portion of the plot shows where the members of each gene set (vertical bars) appear in the ranked list of genes. The bottom portion of the plot shows the value of the ranking metric along the list of ranked genes.

and IRX6 expression ( $r=0.67 ; P<0.05)$, while correlations between $I R X 3$ and other genes in the SRO were weaker $(r<0.41)$. Of the six genes, only $I R X 3, I R X 5$ and IRX6 showed a significant reduction of expression in tumors with $16 q$ deletions (Figure $4 \mathrm{~A}) .{ }^{33}$ Of the ten most common recurrent genomic imbalances in our material (trisomies 12 and 13, segmental gains in 1q, 7q, and 18q, segmental loss in $7 p, 11 p, 11 q$, and $16 q$, and copy number neutral imbalance of $11 \mathrm{p}$; present in 11 to $34 \%$ of cases; Supplemental Tables 1 and 3 at http://ajp. amjpathol.org), only $16 \mathrm{q}$ deletion was associated with differential IRXB gene cluster expression $(P>0.06$ for all other aberrations). When mRNA expression of the six evaluated genes were compared between cases with and without extra-renal extension of tumor disease, only $I R X 3, I R X 5$, and IRX6 showed a significantly lower expression in cases with extra-renal disease, while the expression of LPCAT2, CES1, and MMP2 did not differ between these groups of patients (Figure 4B). ${ }^{33}$ Taken together, these data suggested a specific association between reduced expression of the IRXB cluster genes, on the one hand, and $16 \mathrm{q}$ deletion and aggressive disease, on the other hand, while a similar association was not found for any of the other genes in the SRO. 
A
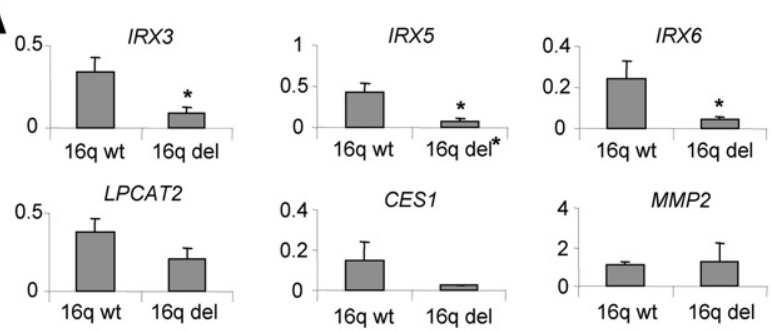

B
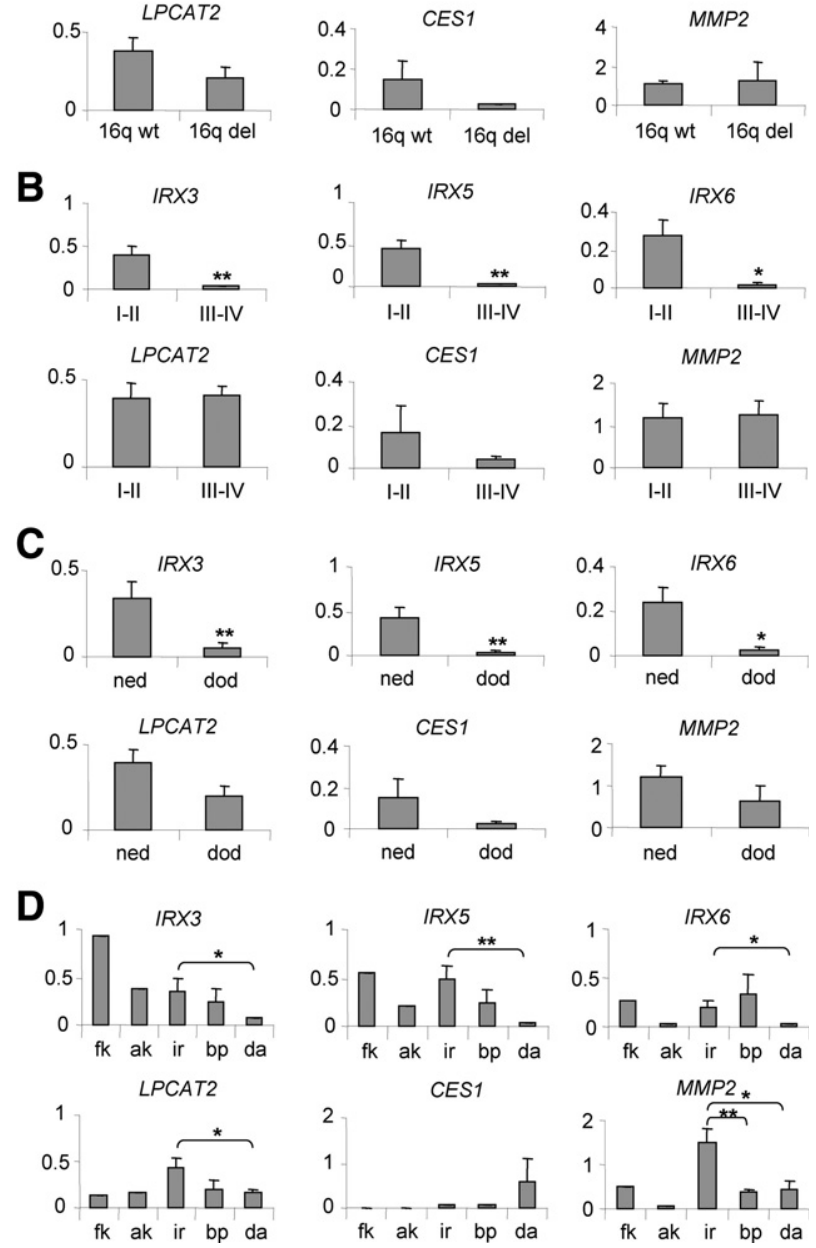

Figure 4. Clinico-pathological correlations to expression of genes in 16q. Based on explorative analyses of an external dataset (Supplemental Figure $2^{33}$ at http://ajp.amjpathol.org), six genes in the smallest region of overlap were selected for mRNA expression analysis in the 27 tumors from which sufficient material for mRNA expression was available. A: Relative mRNA expression in tumors with $16 \mathrm{q}$ deletion (16q del) compared to tumors with wild-type/nondeleted 16q (16q wt). B: Relative mRNA expression in tumors from cases with tumor confined to the kidney (stages I and II) compared with cases with extra-renal disease (stages III and IV). C: Relative mRNA expression levels in tumors from patients exhibiting no evidence of disease after follow-up (ned) compared to those that died of disease (dod). D: Relative mRNA expression levels in fetal kidney (fk), adult kidney (ak), blastemal type (b), diffusely anaplastic (da), and intermediate risk (ir) WTs; ir contains tumors of stromal, epithelial, mixed, and regressive types. All mRNA levels were determined by quantitative PCR analyses, and data were normalized using four reference genes (SDHA, ALAS1, ACTB, and GUSB). Error bars denote a confidence interval of $95 \%$. The $\mathrm{fk}$ and ak bars reflect triplicate analyses of the same material. ${ }^{*} P<0.05,{ }^{* *} P<0.01$ (Student's $t$-test, unequal variance). Differences that were not significant are not annotated.

\section{IRXB Cluster Expression Correlates to Clinico-Pathological Features}

Tumors from patients who later died of disease showed strongly reduced expression of all three IRXB cluster genes compared to tumors from patients with no evidence of disease (Figure 4C). ${ }^{33}$ In contrast, none of the

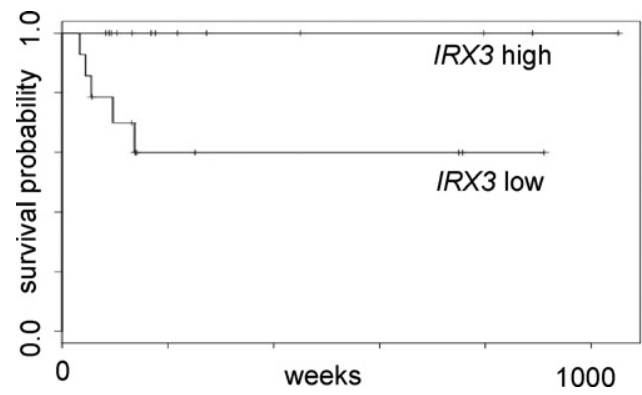

Figure 5. IRX3 expression and survival. Kaplan-Meier plot of tumors with higher and lower than median IRX3 expression (0.15), respectively. mRNA levels were determined as described in the legend to Figure 4. Low IRX3 expression is associated with a lower probability of disease free survival ( $P=$ $0.02, \log$ rank test)

other three SRO genes evaluated in our series of tumors (LPCAT2, CES1, MMP2) showed a significantly different expression between tumors of survivors and nonsurvivors. The distinction between IRXB cluster genes and the other SRO genes was less clear-cut when mRNA expression was compared among histopathological tumor subtypes. There was a wide variability in expression of the IRXB genes among tumors within most subtypes, including blastemal, stromal, epithelial, and mixed types of tumors (Figure $4 \mathrm{D}^{33}$; material was not available from any completely necrotic, low-risk, tumor). Tumors with diffuse anaplasia, in our series dominated by anaplastic blastema, showed a consistently low expression of all three IRXB cluster genes. There was also a lower expression of IRXB cluster genes in adult than in fetal kidney, well in accordance with high expression during nephrogenesis. However, also expression of LPCAT2 and MMP2 showed differential expression in tumors of different histopathological subtypes. Because the mRNA expression values of the IRXB cluster genes were tightly correlated, survival analysis was performed using $I R X 3$ as an indicator of IRXB cluster expression. Kaplan-Meier survival analyses showed a lower probability of disease-free survival for cases with low IRX3 expression compared to those with high expression, when patients were divided into two groups according to ranked IRX3 expression (lower and higher than median expression, respectively; Figure 5). In fact, survival was $100 \%$ in the group with high IRX3 expression. Deletion of $16 q$ was associated with only a borderline significant lower probability of survival in the entire material but showed a stronger association with poor outcome in the group of patients with stage III-IV disease $(P=0.07$ and 0.005 , respectively).

To validate whether these clinico-pathological associations were to some extent specific for IRXB cluster genes or whether similar correlations could be found also for other known nephrogenesis genes selected from the literature, we also quantified mRNA levels in our material for SALL1, LRP2, WT1, BMP7, WNT4, and PAX2. Several of these genes showed a clear difference in their expression in WTs compared to normal fetal and adult kidney tissue, but none of the genes showed a significant correlation between its mRNA expression and histology or survival (Supplemental Figure 3 at http://ajp.amjpathol.org). Taken together, our limited material precluded regular multivariate 
analysis of survival but nevertheless showed an association between low expression of IRXB cluster genes and aggressive clinico-pathological features including diffuse anaplasia, high stage, and low survival.

\section{IRX3 Expression Correlates to Gene Sets Involved in Tubulogenesis}

To address potential correlations between the IRXB cluster genes and other genes involved in differentiation/ morphogenesis, we then performed Pearson correlation analysis between mRNA expression levels of $I R X 3$ and IRX5, respectively, and the expression of the other 54,623 genes for which reporters were available in the external dataset (no reporter was available for IRX6). When the subset of genes showing a positive correlation to IRX3 and IRX5 (Supplemental Table 4, A and B at http:// ajp.amjpathol.org), respectively, were tested for overrepresentation in distinct biological processes according to the Gene Ontology Consortium (http://www. geneontology. org/), the IRX3-correlating gene set was found to be strongly overrepresented in processes related to development and morphogenesis (8/9 processes with significant overrepresentation of this gene set; Supplemental Table $4 \mathrm{C}^{33}$ at $h$ ttp://ajp.amjpathol.org). In contrast, the IRX5-correlating gene set was overrepresented in highly diverse processes, including catabolism, cell adhesion, and cell-cell signaling and with developmental processes only in neural systems (Supplemental Table $4 D^{33}$ at $h$ ttp://ajp.amjpathol.org).

To clarify the biological role of IRX3 in Wilms tumor further, we then performed principal component analysis (PCA) of the gene expression pattern in the external dataset. PCA is a statistical method by which a high number of possibly correlated variables are transformed into a smaller number of uncorrelated variables referred to as principal components, of which the first principal component accounts for as much of the variability in the data as possible, and each succeeding component accounts for as much of the remaining variability as possible. ${ }^{36}$ This revealed a clustering of WTs with high IRX3 expression along the line of the second principal component (Figure 3B), ${ }^{33}$ indicating that tumors with high IRX3 levels had an expression profile that was overall distinct from cases with low IRX3 expression. Despite the strong correlation between $I R X 3$ and $I R X 5$, a similar clustering was not observed for IRX5 (data not shown).

We then performed GSEA to characterize gene sets correlated positively or negatively with IRX3 expression in Wilms tumor, in further detail. GSEA can be used to determine whether a priori determined gene sets correlate to specific biological states, the latter of which can be defined as a rank ordered set of genes. For this purpose, two types of ranked gene lists were created from the expression dataset. The first gene list was ranked according to the Pearson correlation $r$ values between the IRX3 probe and the other reporters in the array. The second list was ranked according to the mean foldchange in expression level between tumors in the IRX3high and the IRX3-low cluster identified by PCA. Compar- ing these two lists by GSEA to gene sets available through the KEGG database and the Gene Ontology Consortium revealed similar results for the two different ranked lists used (Supplemental Table 5 at http://ajp. amjpathol.org). Gene sets enriched for in tumors with high IRX3 expression included genes involved in transmembrane transport and ion channel genes expressed in the renal tubules. Tumors with high IRX3 expression were also enriched for expression of Notch pathway genes (HSA04330 and HSA0432OM; Figure 3C) ${ }^{33}$ eg, CREBBP, HES1, JAG1, and NOTCH1-4. Notch pathway genes are coexpressed in multipotent epithelial progenitors in early nephrons and are believed to have an important role in proximal-distal patterning of tubules in the developing kidney. ${ }^{37}$ In addition, these tumors were enriched for genes involved in Rho signal transduction (GO:0007266). The Rho family of GTPases has been demonstrated to be involved in early development of epithelial cell polarity and renal tubule formation. ${ }^{38,39}$ Other gene sets overrepresented in WTs with high IRX3 expression included ribosomal genes, cell-cell signaling genes, and structural protein genes. In contrast, gene sets enriched for in tumors with low IRX3 expression predominantly comprised genes involved in cell cycle progression, including several mitotic genes (Figure 3D), ${ }^{33}$ and genes coding for proteins involved in chromatin formation. In fact, of the top ten gene ontology gene sets identified by the Pearson correlation and the fold-difference lists, respectively, 9/10 and $7 / 10$ were involved in cell cycle progression or chromatin formation, strongly supporting a predominantly proliferative phenotype of tumors with low IRX3 expression. Thus, of the eight genes that could be validated through the external dataset, only IRX3 fulfilled the dual criteria of a potential role in renal morphogenesis and correlation to aggressive disease in WTs.

\section{IRX3 Protein Expression Occurs Predominantly in Epithelial Elements}

Little is known about the expression of IRX3 in the human kidney. In the murine embryonic kidney Irx3 gene expression first becomes apparent in early comma-shaped bodies, and in S-shaped bodies it is confined to intermediate domains of the developing nephron. ${ }^{23}$ In the murine postnatal kidney, Ir $\times 3$ mRNA expression is retained in specific nephron segments of the loop of Henle, including the distal part of proximal tubules. To localize IRX3-expressing cells in the human postnatal kidney, we performed immunofluorescence with a monoclonal antibody directed against human IRX3 on non-neoplastic kidney tissue present in four of the five tissue specimens used to localize cells with $16 \mathrm{q}$ deletions (the fifth did not contain normal kidney tissue). This revealed that IRX3-immunoreactive cells were confined to cortical renal tubules, consistent with the expression pattern observed in the murine tissue on mRNA level (Figure 6A). IRX3-positive cells were also detected in the majority of tubular epithelial tumor elements in the tissue sections used to localize cells with $16 \mathrm{q}$ deletions (Figure 6, B-D; Supplemental Figure 1D at http://ajp.amjpathol.org), while approxi- 

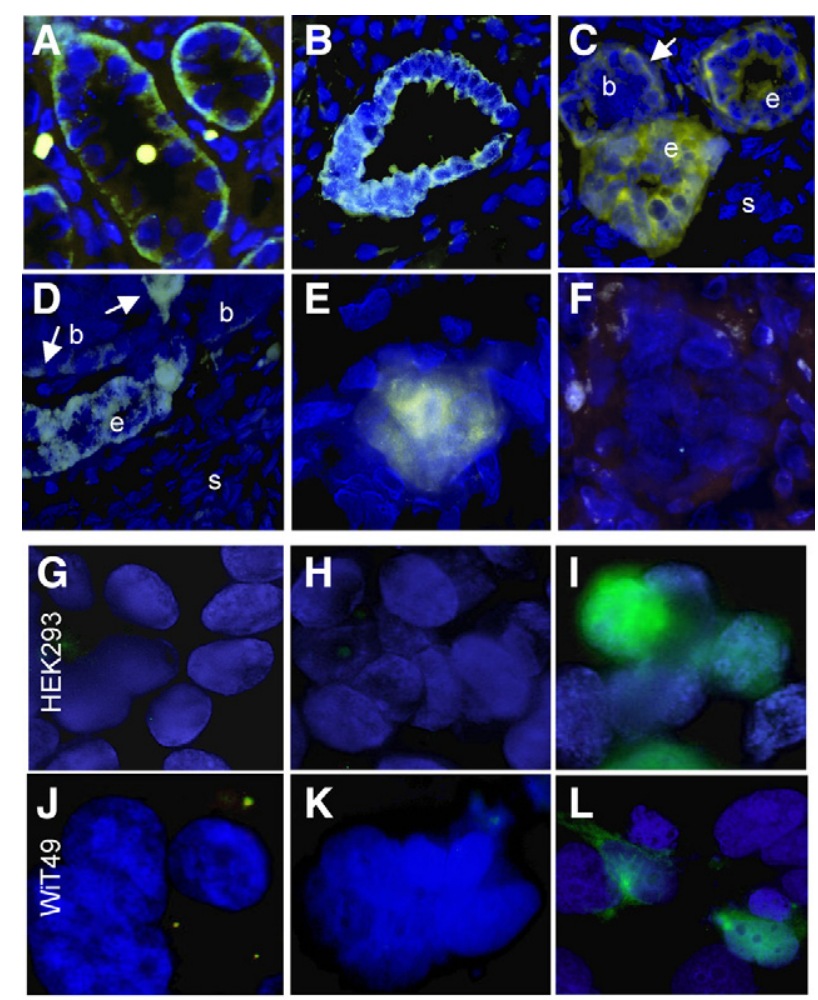

vector only

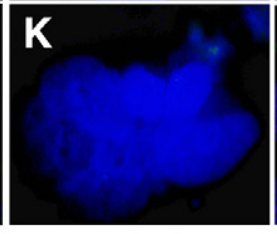

reagent only

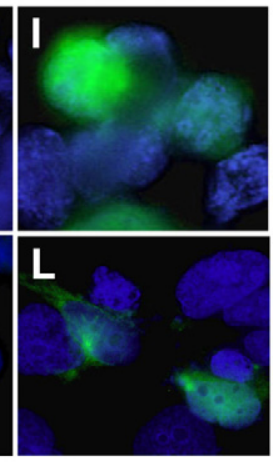

IRX3-YFP
Figure 6. IRX3 protein expression. $\mathbf{A}$ and B: IRX3 expression (green) in normal renal tubules and in mature epithelial tumor elements, respectively, in case 20; note the surrounding negative stromal tumor element in $\mathbf{B}$ nuclear staining was obtained with DAPI (blue). C and D: Expression in maturing epithelial (e) elements and at the periphery (arrows) of blastemal islands (b) but not in stromal elements (s) in 16q-intact cell populations in cases 7 and 27. E: A focus of blastemal cells expressing IRX3 in a 16q-intact blastemal element in case 7 . F: Fluorescence-negative 16q-deleted blastemal element in case 20. G-L: HEK293D (G-I) and WiT49 (J-L) cells treated by the IOH27948-pdEYFP-N1gen vector only ( $\mathbf{G}$ and $\mathbf{J}$ ), FuGENE Transfection reagent only ( $\mathbf{H}$ and $\mathbf{K}$ ), and the vector together with FuGENE Transfection reagent (I and $\mathbf{L})$. Successfully transfected cells (I and $\mathbf{L}$ ) exhibit predominantly cytoplasmic localization of IRX3-YFP. All fluorescence microscopy images were acquired using a $\times 100$ objective and subsequently rescaled digitally.

mately $20 \%$ of the blastemal elements contained IRX3positive cells (Figure 6E). These cells were often confined to the peripheries of blastemal islands where $16 q$ copy number had previously been shown to be normal by FISH, typically adjacent to IRX3-positive epithelial elements (Figure 6, C and D). No IRX3-positive cells were detected in the blastemal or blastic-anaplastic elements in which $16 q$ deletion had been demonstrated (Figure 6F).

The fluorescent staining pattern in IRX3-positive cells was predominantly cytoplasmic. To validate this staining pattern, a YFP-coupled IRX3 vector was overexpressed in the human embryonic kidney cell line HEK293 as well as in the Wilms tumor cell line WiT49. No YFP-positive cells were observed after treating the cells with the vector in the absence of transfection agent (Figure 6, G and J) nor in cells subjected to treatment with the transfection reagent only (Figure 6, $\mathrm{H}$ and $\mathrm{K}$ ). In contrast, successfully transfected YFP-positive cells had a predominantly cytoplasmic staining, consistent with the results obtained by immunofluorescence (Figure 6, I and L). Taken together, these results indicated that IRX 3 is regularly expressed in postnatal human kidney and in immature Wilms tumor epithelium, in analogy with its expression in the postnatal murine and embryonic kidney, respectively. The observation that expression in blastemal cells was confined to peripherally located cells with normal $16 q$ copy number adjacent to epithelial elements, suggested that IRX3 expression promoted blastemal-epithelial differentiation in these areas. In contrast, 16q-deleted populations were uniformly IRX3-negative, showing that cells with hemizygous IRX3 loss expressed the corresponding protein at levels below the detection limit for immunofluorescence.

\section{Absence of IRX3 Sequence Mutations in 16q-Deleted WTs}

Of the IRXB cluster genes, only IRX3 has been previously shown to have a role in mammalian nephrogenesis. ${ }^{23}$ Our bio-informatic analyses indicated an analogous role for IRX3, but not for IRX5, in tubular maturation in Wilms tumor. Based on this, IRX3 appeared to be the strongest candidate gene for disruption of tubulogenesis in Wilms tumor through $16 \mathrm{q}$ deletion. To evaluate whether the observed large-scale deletions of IRX3 coexisted with point-mutations in the remaining allele, we sequenced the entire coding region in six WTs (patients 4, 7, 14, 20, 21, and 27) with $16 q$ deletions and one Wilms tumor without 16q deletion (case 18). Two deviations from the IRX3 reference sequence (1851 $\mathrm{T}$ to $\mathrm{C}$ in all tumors and $2207 \mathrm{G}$ to $\mathrm{T}$ in cases 14 and 18) were detected. However, these variants were also found in control DNA from a healthy female and are previously published polymorphisms. Thus, the hemizygous deletion of IRX3 was not coupled to mutations in the remaining allele in our material.

\section{Discussion}

A recent study has shown that $16 q$ deletions are rarely found in the perilobar nephrogenic rests of Wilms tumor patients harboring this deletion in the tumor cells. ${ }^{34}$ Based on this, the authors suggested that $16 q$ deletions are late events in Wilms tumorigenesis, preceded by genetic and epigenetic up-regulation of IGF2. Consistent with this, we found that $16 q$ deletions are typically confined to blastemal components with or without anaplastic features in Wilms tumor and are rare/absent in nephrogenic rests and maturing tumor elements (stromal and epithelial). Our SNP-based aCGH data revealed that the most commonly deleted interval contained the IRXB gene cluster, including $I R X 3$, a recently identified master regulator of tubular patterning in the embryonic kidney. ${ }^{23}$ Of the genes present in the SRO, only the three IRXB genes showed a consistent correlation of their expression to aggressive clinico-pathological features including extrarenal spread of disease and survival. However, the IRXB genes are unlikely to be the only gene set in $16 q$ with a role in driving the progression toward more aggressive disease in WTs with $16 q$ deletions. Previous attempts to 
delineate an SRO for $16 q$ deletions in Wilms tumor, using either loss of heterozygosity of polymorphic markers or aCGH have shown that most deletions encompass large genomic segments, often the entire 16q arm. ${ }^{19,20,22,40,41}$ Grundy et al identified two commonly lost genomic segments, one in distal $16 q$ and one in proximal $16 q$ (D16S419-D1IS512), of which the latter covers the SRO identified in the present study. ${ }^{19}$ Austruy and co-workers also identified a common region of loss in proximal $16 q$ (D16S308-D16S320), covering a genomic segment including the IRXB cluster. ${ }^{40}$ Wittmann et al identified a large segment of common allelic loss, in which one of the most commonly lost markers was D16S3253 located between IRX3 and IRX5. ${ }^{22}$ Hence, even if the SRO identified in our study was largely based on a single case with an unusually small deletion, it is consistent with previous attempts to narrow down a commonly lost segment in 16q. Needless to say, the subgroup of tumors showing an isolated loss of segments distal to 16q12-21 cannot be accounted for by deletion of IRXB cluster genes. ${ }^{19,42,43}$ However some of the studies identifying such isolated distal deletions used relatively few polymorphic markers, therefore not excluding more proximal regions of focal allelic imbalance in 16q.

Reduced expression of IRX3, IRX5, and IRX6 was associated with extra-renal spread (stages III and IV) and death in the present study. In fact, low IRXB gene expression showed a stronger correlation to unfavorable clinico-pathological parameters than did $16 q$ deletion. Of the seven patients dying of disease, only three exhibited deletions in 16q while all five cases in which expression could be quantified had a uniformly low mRNA expression of IRX3, IRX5, and IRX6 (Figure 4C). ${ }^{33}$ The discrepancies between 16q status and IRXB cluster gene expression could reflect genetic intratumor heterogeneity in our Wilms tumor material, leading to failure to detect $16 q$ deletions by SNP-based aCGH in cases with low IRXB expression because cell populations harboring such deletions were not present in a sufficient amount in the tissue used for genomic analysis. According to previous validations, our genomic analysis approach will detect deletions present in at least $20 \%$ of cells in a near-diploid cell population. ${ }^{28}$ Lowering the detection threshold will produce signal:noise ratios that are too low for robust analysis. Considering our finding of $16 q$ deletions only in a minority of cells in most tumor tissue sections, it is therefore possible that some cases with $16 \mathrm{q}$ deletions were missed. A more sensitive approach, such as quantitative PCR, might have given a higher detection rate but would still prove to be of little value if the specimen used for genomic analysis failed to contain cells from the 16qdeleted clone. On the other hand, the failure to detect $16 q$ deletions in cases with low IRXB expression levels could indicate that deletion of $16 \mathrm{q}$ may be only one possible route toward disease progression mediated by reduced expression of IRX3. Epigenetic or trans-effect regulation of $I R X 3$ is further supported by the finding that IRX3 protein expression by immunofluorescence was below the detection limit in elements with hemizygous deletions, indicating that a loss of one of the two IRX3 alleles was sufficient to dramatically reduce IRX3 levels. This, together with the lack of sequence mutations of $I R X 3$ in 16q-deleted tumors, prompt future studies of 16q12-21 chromatin modification and upstream genes involved in regulating expression of IRXB genes in Wilms tumor.

In the early mouse embryo Irx 3 is selectively expressed in the developing metanephric blastema and early tubules. ${ }^{23}$ In Xenopus, knock-down of Irx1 or Irx2 results in no visible defects, while Irx3 knock-down gives rise to malformations and absence of pronephric kidneys, inferring that Irx3 is required to specify the distal part of the proximal tubule and the entire intermediate tubule. ${ }^{23}$ In contrast, Irx5 and Irx6 were found not to be expressed during pronephric kidney development in Xenopus ${ }^{44}$ or during embryonic kidney development in the mouse. ${ }^{45}$ These previous studies thus indicated a more prominent role for IRX3 than for IRX5 and IRX6 in driving blastemalepithelial transition in vertebrates. We found that the expression of the IRX3 protein in tissue sections was predominantly cytoplasmic, contrary to what would be expected from previous characterization of IRX3 as a transcription factor. To our knowledge, there are no previous studies of IRX3 protein localization in the vertebrate kidney. The cytoplasmic expression pattern was found both in Wilms tumor and in adjacent normal kidney tissue, arguing against cytoplasmic expression being a part of IRX3 de-regulation in tumors. The predominantly cytoplasmic localization of IRX3 was corroborated by in vitro expression in two cell lines, with concordant results for human embryonic kidney (HEK293) and Wilms tumor cells (WiT49). Our data does not exclude an additional minor nuclear pool of IRX3. It therefore remains a question for further studies whether the predominantly cytoplasmic localization corresponds to a situation where IRX 3 is continuously shuttled between the cytoplasm and nucleus, with its main function still being dependent on DNA binding and transcription regulation or whether there are also other functions of IRX3 mediated by cytoplasmic binding partners.

We found that the IRX3 protein was expressed predominantly in cortical tubules in the human kidney. IRX3 was also expressed in epithelial Wilms tumor elements and non-16q-deleted blastemal areas of Wilms tumor, which are believed to mimic the immature nephrogenic tubules and the metanephric blastema, respectively. Presumably, the IRX3-expressing cells at the peripheries of blastemal islands corresponded to committed epithelial progenitor populations, explaining their physical proximity to tubular elements. The role of IRX3 in driving epithelial lineage commitment in Wilms tumor was supported by the finding that gene sets involved in tubular differentiation, including the Notch- and Rho-pathways, were enriched in highly $I R X 3$-expressing tumors, while a similar correlation to gene sets involved in morphogenesis could not be found for IRX5. In contrast, IRX3 was not expressed in regular or anaplastic blastema with 16 q deletions. Our findings thus suggest that IRX3 has a role in promoting mesenchymal-epithelial transition in non-16qdeleted Wilms tumor in a fashion similar to its role in the developing kidney. Consequently, loss of the normal capacity for IRX3 expression through 16q deletion or other mechanisms in immature tumor elements could consoli- 
date the blastemal-epithelial differentiation block underlying Wilms tumor formation and tilt the blastemal-epithelial balance toward increased self-renewal of blastemal cells and possibly also the development of anaplasia. However, in contrast to previous studies in Xenopus and mouse, we found expression also of IRX5 and IRX6 in fetal human kidney and an expression of these genes in Wilms tumor that closely paralleled that of $I R X 3$. This indicates that also the other members of the IRXB gene cluster may have a role in human nephrogenesis, and it cannot be excluded that these genes have a role similar to $I R X 3$ in consolidating differentiation block in Wilms tumor.

Few studies have addressed the mechanism behind the development of anaplasia. Our finding that $16 \mathrm{q}$ deletions were present in adjacent blastemal and blastemal-anaplastic elements indicates that these components share a common clonal origin. Low IRXB gene cluster expression was correlated to diffuse anaplasia, which in our series of tumors was typically of the blastemal-anaplastic type, with no tumor having a predominantly epithelial-anaplastic or stromal-anaplastic pattern. Tumors classified as diffusely anaplastic in our series of tumors typically contained $>80 \%$ anaplastic elements, which could explain the consistently low IRXB expression found in these tumors. This suggests that the poor survival of patients with tumors having low IRXB cluster expression was strongly associated with reduced capacity for differentiation of blastemal elements and a shift toward anaplastic features. We have previously shown that anaplasia is associated with the establishment of widespread genomic instability caused by telomere dysfunction. ${ }^{46}$ This type of telomere-dependent chromosomal instability was also found in blastemal elements but not in epithelial or stromal elements in that study. It is thus feasible that blastemal cells with anaplastic features are derived from regular blastemal cells at least partly through mutations resulting from such genomic instability. The finding in the present study that tumors with low IRX3 expression were almost exclusively enriched for gene sets involved in cell cycle progression suggests that loss of IRX3 could drive blastemal-anaplastic transition by promoting increased proliferation of blastemal cells, in turn leading to progressive telomere attrition and further genomic rearrangements.

\section{References}

1. Ko EY, Ritchey ML: Current management of Wilms' tumor in children. J Pediatr Urol 2009, 5:56-65

2. Rivera MN, Haber DA: Wilms' tumour: connecting tumorigenesis and organ development in the kidney. Nat Rev Cancer 2005, 5:699-712

3. Li CM, Guo M, Borczuk A, Powell CA, Wei M, Thaker HM, Friedman R, Klein U, Tycko B: Gene expression in Wilms' tumor mimics the earliest committed stage in the metanephric mesenchymal-epithelial transition. Am J Pathol 2002, 160:2181-2190

4. Li W, Kessler P, Williams BR: Transcript profiling of Wilms tumors reveals connections to kidney morphogenesis and expression patterns associated with anaplasia. Oncogene 2005, 24:457-468

5. Beckwith JB, Kiviat NB, Bonadio JF: Nephrogenic rests, nephroblastomatosis, and the pathogenesis of Wilms' tumor. Pediatr Pathol 1990, 10:1-36

6. Kreidberg JA, Sariola H, Loring JM, Maeda M, Pelletier J, Housman D,
Jaenisch R: WT-1 is required for early kidney development. Cell 1993, 74:679-691

7. Maiti S, Alam R, Amos Cl, Huff V: Frequent association of beta-catenin and WT1 mutations in Wilms tumors. Cancer Res 2000, 60:62886292

8. Kispert A, Vainio S, McMahon AP: Wnt-4 is a mesenchymal signal for epithelial transformation of metanephric mesenchyme in the developing kidney. Development 1998, 125:4225-4234

9. Rivera MN, Kim WJ, Wells J, Driscoll DR, Brannigan BW, Han M, Kim JC, Feinberg AP, Gerald WL, Vargas SO, Chin L, lafrate AJ, Bell DW, Haber DA: An X chromosome gene. WTX, is commonly inactivated in Wilms tumor Science 2007, 315:642-645

10. Major MB, Camp ND, Berndt JD, Yi X, Goldenberg SJ, Hubbert C, Biechele TL, Gingras AC, Zheng N, Maccoss MJ, Angers S, Moon RT: Wilms tumor suppressor WTX negatively regulates WNT/beta-catenin signaling. Science 2007, 316:1043-1046

11. Fukuzawa R, Heathcott RW, More HE, Reeve AE: Sequential WT1 and CTNNB1 mutations and alterations of beta-catenin localisation in intralobar nephrogenic rests and associated Wilms tumours: two case studies. J Clin Pathol 2007, 60:1013-1016

12. Park S, Bernard A, Bove KE, Sens DA, Hazen-Martin DJ, Garvin AJ, Haber DA: Inactivation of WT1 in nephrogenic rests, genetic precursors to Wilms' tumour. Nat Genet 1993, 5:363-367

13. Wegert J, Wittmann S, Leuschner I, Geissinger E, Graf N, Gessler M: WTX inactivation is a frequent, but late event in Wilms tumors without apparent clinical impact. Genes Chromosomes Cancer 2009, 48:1102-1111

14. Ruteshouser EC, Robinson SM, Huff V: Wilms tumor genetics: mutations in WT1. WTX, and CTNNB1 account for only about one-third of tumors Genes Chromosomes Cancer 2008, 47:461-470

15. Vujanic GM, Sandstedt B: The pathology of Wilms' tumour (nephroblastoma): The International Society of Paediatric Oncology approach. J Clin Pathol 2009, 63:102-109

16. Vujanic GM, Sandstedt B, Harms D, Kelsey A, Leuschner I, de Kraker $\mathrm{J}$ : Revised International Society of Paediatric Oncology (SIOP) working classification of renal tumors of childhood. Med Pediatr Oncol 2002, 38:79-82

17. Verschuur AC, Vujanic GM, van Tinteren H, Pritchard-Jones K, de Kraker J, Sandstedt B: Stromal and epithelial predominant Wilms tumour has an excellent prognosis: the SIOP 9301 experience. Pediatr Blood Cancer 2010, 55:233-238

18. Grundy PE, Telzerow PE, Breslow N, Moksness J, Huff V, Paterson MC: Loss of heterozygosity for chromosomes $16 q$ and $1 p$ in Wilms' tumors predicts an adverse outcome. Cancer Res 1994, 54:23312333

19. Grundy RG, Pritchard J, Scambler P, Cowell JK: Loss of heterozygosity on chromosome 16 in sporadic Wilms' tumour. Br J Cancer 1998, 78:1181-1187

20. Klamt B, Schulze M, Thate C, Mares J, Goetz P, Kodet R, Scheulen W, Weirich A, Graf N, Gessler M: Allele loss in Wilms tumors of chromosome arms 11q, 16q, and 22q correlate with clinicopathological parameters. Genes Chromosomes Cancer 1998, 22:287-294

21. Messahel B, Williams R, Ridolfi A, A'Hern R, Warren W, Tinworth L, Hobson R, Al-Saadi R, Whyman G, Brundler MA, Kelsey A, Sebire N, Jones C, Vujanic G, Pritchard-Jones K: Allele loss at 16q defines poorer prognosis Wilms tumour irrespective of treatment approach in the UKW1-3 clinical trials: a Children's Cancer and Leukaemia Group (CCLG) Study. Eur J Cancer 2009, 45:819-826

22. Wittmann S, Zirn B, Alkassar M, Ambros P, Graf N, Gessler M: Loss of $11 \mathrm{q}$ and $16 \mathrm{q}$ in Wilms tumors is associated with anaplasia, tumor recurrence, and poor prognosis. Genes Chromosomes Cancer 2007, 46:163-170

23. Reggiani L, Raciti D, Airik R, Kispert A, Brandli AW: The prepattern transcription factor Ir×3 directs nephron segment identity. Genes Dev 2007, 21:2358-2370

24. Gisselsson D: Refined characterisation of chromosome aberrations in tumours by multicolour banding and electronic mapping resources. Methods Cell Sci 2001, 23:23-28

25. Alami J, Williams BR, Yeger H: Derivation and characterization of a Wilms' tumour cell line. WiT 49 Int J Cancer 2003, 107:365-374

26. Gisselsson D, Hakanson U, Stoller P, Marti D, Jin Y, Rosengren AH, Stewenius $Y$, Kahl F, Panagopoulos I: When the genome plays dice: circumvention of the spindle assembly checkpoint and near-random 
chromosome segregation in multipolar cancer cell mitoses. PLoS One 2008, 3:e1871

27. Staaf J, Vallon-Christersson J, Lindgren $D$, Juliusson $G$, Rosenquist $R$, Hoglund M, Borg A, Ringner M: Normalization of Illumina Infinium whole-genome SNP data improves copy number estimates and allelic intensity ratios. BMC Bioinformatics 2008, 9:409

28. Staaf J, Lindgren D, Vallon-Christersson J, Isaksson A, Goransson H, Juliusson G, Rosenquist R, Hoglund M, Borg A, Ringner M: Segmentation-based detection of allelic imbalance and loss-of-heterozygosity in cancer cells using whole genome SNP arrays. Genome Biol 2008, 9:R136

29. Glenn ST, Jones CA, Liang P, Kaushik D, Gross KW, Kim HL: Expression profiling of archival renal tumors by quantitative PCR to validate prognostic markers. Biotechniques 2007, 43:639-640, 642-643, 647

30. Ohl F, Jung M, Xu C, Stephan C, Rabien A, Burkhardt M, Nitsche A, Kristiansen G, Loening SA, Radonic A, Jung K: Gene expression studies in prostate cancer tissue: which reference gene should be selected for normalization? J Mol Med 2005, 83:1014-1024

31. Vandesompele J, De Preter K, Pattyn F, Poppe B, Van Roy N, De Paepe A, Speleman F: Accurate normalization of real-time quantitative RT-PCR data by geometric averaging of multiple internal control genes. Genome Biol 2002, 3:RESEARCH0034

32. Vandesompele J, De Paepe A, Speleman F: Elimination of primerdimer artifacts and genomic coamplification using a two-step SYBR green I real-time RT-PCR. Anal Biochem 2002, 303:95-98

33. Kort EJ, Farber L, Tretiakova M, Petillo D, Furge KA, Yang XJ, Cornelius A, Teh BT: The E2F3-Oncomir-1 axis is activated in Wilms' tumor. Cancer Res 2008, 68:4034-4038

34. Vuononvirta R, Sebire NJ, Dallosso AR, Reis-Filho JS, Williams RD, Mackay A, Fenwick K, Grigoriadis A, Ashworth A, Pritchard-Jones K, Brown KW, Vujanic GM, Jones C: Perilobar nephrogenic rests are nonobligate molecular genetic precursor lesions of insulin-like growth factor-II-associated Wilms tumors. Clin Cancer Res 2008, 14:76357644

35. Stewenius $Y$, Jin Y, Ora I, Panagopoulos I, Moller E, Mertens F, Sandstedt B, Alumets J, Akerman M, Merks JH, de Kraker J, Gisselsson D: High-resolution molecular cytogenetic analysis of Wilms tumors highlights diagnostic difficulties among small round cell kidney tumors. Genes Chromosomes Cancer 2008, 47:845-852
36. Jolliffe I: Principal Component Analysis. New York, Springer-Verlag New York Inc, 2002, pp 1-9

37. Cheng HT, Kim M, Valerius MT, Surendran K, Schuster-Gossler K, Gossler A, McMahon AP, Kopan R: Notch2, but not Notch1, is required for proximal fate acquisition in the mammalian nephron. Development 2007, 134:801-811

38. Jou TS, Nelson WJ: Effects of regulated expression of mutant RhoA and Rac1 small GTPases on the development of epithelial (MDCK) cell polarity. J Cell Biol 1998, 142:85-100

39. Rogers KK, Jou TS, Guo W, Lipschutz JH: The Rho family of small GTPases is involved in epithelial cystogenesis and tubulogenesis. Kidney Int 2003, 63:1632-1644

40. Austruy E, Candon S, Henry I, Gyapay G, Tournade MF, Mannens M, Callen D, Junien C, Jeanpierre C: Characterization of regions of chromosomes 12 and 16 involved in nephroblastoma tumorigenesis. Genes Chromosomes Cancer 1995, 14:285-294

41. Rassekh SR, Chan S, Harvard C, Dix D, Qiao Y, Rajcan-Separovic E: Screening for submicroscopic chromosomal rearrangements in Wilms tumor using whole-genome microarrays. Cancer Genet Cytogenet 2008, 182:84-94

42. Safford SD, Goyeau D, Freemerman AJ, Bentley R, Everett ML, Grundy PE, Skinner MA: Fine mapping of Wilms' tumors with 16q loss of heterozygosity localizes the putative tumor suppressor gene to a region of 6.7 megabases. Ann Surg Oncol 2003, 10:136-143

43. Yuan E, Li CM, Yamashiro DJ, Kandel J, Thaker H, Murty VV, Tycko B: Genomic profiling maps loss of heterozygosity and defines the timing and stage dependence of epigenetic and genetic events in Wilms tumors. Mol Cancer Res 2005, 3:493-502

44. Alarcon P, Rodriguez-Seguel E, Fernandez-Gonzalez A, Rubio R, Gomez-Skarmeta JL: A dual requirement for Iroquois genes during Xenopus kidney development. Development 2008, 135:3197-3207

45. Houweling AC, Dildrop R, Peters T, Mummenhoff J, Moorman AF, Ruther U, Christoffels VM: Gene and cluster-specific expression of the Iroquois family members during mouse development. Mech Dev 2001, 107:169-174

46. Stewenius $Y$, Jin $Y$, Ora I, de Kraker J, Bras J, Frigyesi A, Alumets J, Sandstedt B, Meeker AK, Gisselsson D: Defective chromosome segregation and telomere dysfunction in aggressive Wilms' tumors. Clin Cancer Res 2007, 13:6593-6602 